\title{
Functional MRI approach to developmental methylmercury and polychlorinated biphenyl neurotoxicity
}

\section{Citation}

White, Roberta F., Carole L. Palumbo, Deborah A. Yurgelun-Todd, Kristin J. Heaton, Pal Weihe, Frodi Debes, and Philippe Grandjean. 2011. "Functional MRI Approach to Developmental Methylmercury and Polychlorinated Biphenyl Neurotoxicity." NeuroToxicology 32 (6) (December): 975-980. doi:10.1016/j.neuro.2011.04.001.

\section{Published Version}

doi:10.1016/j.neuro.2011.04.001

\section{Permanent link}

http://nrs.harvard.edu/urn-3:HUL.InstRepos:34767899

\section{Terms of Use}

This article was downloaded from Harvard University's DASH repository, and is made available under the terms and conditions applicable to Other Posted Material, as set forth at http:// nrs.harvard.edu/urn-3:HUL.InstRepos:dash.current.terms-of-use\#LAA

\section{Share Your Story}

The Harvard community has made this article openly available.

Please share how this access benefits you. Submit a story.

Accessibility 


\title{
Functional MRI approach to developmental methylmercury and polychlorinated biphenyl neurotoxicity
}

\author{
Roberta F. White ${ }^{a, b,{ }^{*}}$, Carole L. Palumbo ${ }^{b}$, Deborah A. Yurgelun-Todd ${ }^{c, h}$, Kristin J. $^{2}$ \\ Heaton $^{a, d}$, Pal Weihe $^{e}$, Frodi Debes ${ }^{e}$, and Philippe Grandjean ${ }^{f, g}$
}

aDepartment of Environmental Health, Boston University School of Public Health, Boston, MA, United States bepartment of Neurology, Boston University School of Medicine, Boston, MA, United States 'Department of Psychiatry, Harvard Medical School, Boston, MA, United States ¿United States Army Research Institute of Environmental Medicine, Natick, MA, United States eDepartment of Occupational and Public Health, Faroese Hospital System, Torshavn, Faroe Islands fDepartment of Environmental Health, Harvard School of Public Health, Boston, MA, United States 9Department of Environmental Medicine, University of Southern Denmark, Odense, Denmark hrain Institute, University of Utah, Salk Lake City, UT, USA

\begin{abstract}
Prenatal and early childhood exposure to methylmercury $(\mathrm{MeHg})$ or polychlorinated biphenyls (PCBs) are associated with deficits in cognitive, sensory, motor and other functions measured by neurobehavioral tests. The main objective of this pilot study was to determine whether functional magnetic resonance imaging (fMRI) is effective for visualization of brain function alterations related to neurobehavior in subjects with high prenatal exposure to the two neurotoxicants, $\mathrm{MeHg}$ and PCBs. Twelve adolescents (all boys) from a Faroese birth cohort assembled in 1986-1987 were recruited based on their prenatal exposures to $\mathrm{MeHg}$ and PCB. All underwent fMRI scanning during behavioral tasks at age 15 years. Subjects with high mixed exposure to $\mathrm{MeHg}$ and $\mathrm{PCBs}$ were compared to those with low mixed exposure on fMRI photic stimulation and a motor task. Boys with low mixed exposures showed patterns of fMRI activation during visual and motor tasks that are typical of normal control subjects. However, those with high exposures showed activation in more areas of the brain and different and wider patterns of activation than the low mixed exposure group. The brain activation patterns observed in association with increased exposures to $\mathrm{MeHg}$ and PCBs are meaningful in regard to the known neurotoxicity of these substances. This methodology therefore has potential utility in visualizing structural neural system determinants of exposure-induced neurobehavioral dysfunction.
\end{abstract}

(C) 2011 Elsevier Inc. All rights reserved.

*Corresponding author at: Department of Environmental Health, Boston, University School of Public Health, Boston, MA, United States. Tel.: +1 617638 4620; fax: +1 617638 4857. rwhite@bu.edu (R.F. White).

Competing financial interests declaration

No competing financial interests exist. 


\section{Keywords}

Developmental neurotoxicity; Environmental exposure; Functional magnetic resonance imaging; Methylmercury; Neurotoxicity syndromes; Polychlorinated biphenyls; Prenatal exposure delayed effects

\section{Introduction}

For the past three decades, the detection of subtle, low-dose effects of exposures to neurotoxicants such as lead (Canfield et al., 2003), methylmercury (MeHg) (Cordier et al., 2002; Debes et al., 2006), and polychlorinated biphenyls (PCBs) (Jacobson et al., 1990) on brain functioning in children has received a great deal of attention (Bellinger et al., 2006; Grandjean and Landrigan, 2006). Neurobehavioral tasks are frequently used in these investigations because they are non-invasive and can be administered in a standardized manner (White, 2004).

Based on a variety of domain-specific neuropsychological tests and omnibus intelligence (IQ) tests, converging evidence shows that developmental exposures to MeHg adversely affects several brain functions, although some uncertainties exist, including impacts of mixed exposures among the populations examined, the extent of counterbalancing effects of seafood nutrients, timing of exposures and effects, and critical exposure indicators (Grandjean et al., 2006). Similarly, PCBs are known through animal and human studies to adversely affect brain function, though there is inconsistency across study results with regard to exposure levels and ages at which effects are detected and the specific test measures indicating neurotoxicity (Rice, 2006). As MeHg and PCBs are both contaminants of marine food, co-exposures occur in some populations, thus possibly leading to combined effects (Grandjean et al., 2001).

Although the precise neural mechanisms by which human brain functions are altered, especially in low-dose exposure scenarios, are poorly understood, these neurotoxicants most likely induce a cascade of complex changes within the developing central nervous system, resulting in the behavioral deficits that can be clinically assessed later on. An ideal investigative tool would allow researchers to visualize the functioning brains of exposed individuals while they are engaged in cognitive tasks that are affected by these toxicants. Functional magnetic resonance imaging provides such a tool (Papanicolaou, 1998) and has been used to assess the effects of lead exposure in children (Yuan et al., 2006).

In this pilot study, fMRI techniques were used to visualize activation of specific anatomical brain areas during behavioral tasks among adolescent children with well-defined prenatal exposures to $\mathrm{MeHg}$ and PCBs. The tasks used are associated with functioning of highly specific areas of the brain. This paper compares the findings among adolescents with high and low mixed exposures to MeHg and PCBs on behavioral outcomes assessing the domains of visual processing and manual motor function. 


\section{Materials and methods}

\subsection{Participants}

The 12 study participants were members of a cohort of children established at the three hospitals in the Faroe Islands by two of the authors (PW, PG). This cohort has been well described elsewhere (Grandjean et al., 1997). Briefly, it consists of 1022 children born in 1986-1987, about $75 \%$ of all births. These children were prenatally exposed to $\mathrm{MeHg}$ and PCBs due to maternal consumption of seafood, including pilot whale meat and blubber. At parturition, cord blood and maternal hair samples were collected in order to determine $\mathrm{Hg}$ concentrations. A piece of umbilical cord tissue was also taken, and half of these samples were later analyzed for PCBs and other major organochlorine compounds. Dose-effect relationships between prenatal exposure to $\mathrm{MeHg}$ and cognitive outcomes were seen in several domains at ages 7 and 14, including motor function, reaction time, language, and memory (Debes et al., 2006; Grandjean et al., 1997). The exposure to both substances at the time of clinical assessment was not associated with test performance. Sociodemographic variables affected these associations only marginally.

For the current study, recruitment of participants was designed to select groups of three boys who best represented each of four widely different types of prenatal exposure: high $\mathrm{MeHg}$; high PCB; high mixed exposure; and low mixed exposure. Exposure to $\mathrm{MeHg}$ was defined as cord blood mercury concentration $(\mu \mathrm{g} / \mathrm{L})$. PCB exposure was defined as total cord tissue PCB concentration (ng/g wet weight) based upon the three major congeners: (PCB-138 + PCB-153 + PCB-180) $\times 2$. The high and low mixed exposure groups were identified as the highest and the lowest products of $\mathrm{Hg}$ and PCB concentrations, while the highest and lowest ratios of $\mathrm{Hg} / \mathrm{PCB}$ were used to identify the groups with high $\mathrm{MeHg}$ or high $\mathrm{PCB}$ exposures, respectively. The cohort members identified in this way ranged in age from 14 years, 9 months to 15 years, 7 months, with the median age being 15 years, 0 months. None of the subjects had any neurological diagnosis that might affect their performance, and all of them were right-handed and had birth weights above $2500 \mathrm{~g}$. Any alcohol use during pregnancy was rare in this cohort and no effects were seen in relation to maternal tobacco smoking. Thus, given the homogeneity of this cohort, no attempt was made to match the subjects on parameters other than $\mathrm{MeHg}$ and $\mathrm{PCB}$ (to preserve anonymity, details on individual characteristics are not reported here). All 12 boys and their parents agreed to participate in the study. Consent forms for the study methods and for travel to the United States were signed by the parents. The study received ethical review board approval from the Faroese Ethical Review Committee and the McLean Hospital Institutional Review Board. Only boys were included to facilitate ethical review approval and travel permission to the US from the parents.

Results for mercury and PCB exposure for the adolescents are detailed in Table 1. Analysis of the PCB concentration in stored cord blood from the cohort subjects confirmed the high validity of the cord tissue analyses (Grandjean et al., 2001). The products of mercury and PCB in the high mixed exposure group (high $\mathrm{Hg}$ and high $\mathrm{PCB}$ ) averaged approximately 100-fold greater than the products in the low, mixed exposure group (low Hg and low PCB); each of the two neurotoxicants averaged about 10-fold higher in the highly exposed group. 
Similarly, ratios of $\mathrm{Hg} / \mathrm{PCB}$ for the high $\mathrm{Hg}$ group were almost 100-fold higher than the ratios of $\mathrm{Hg} / \mathrm{PCB}$ in the low $\mathrm{Hg}$ group. The high-PCB group had exposure levels similar to the high, mixed group, while the high $\mathrm{Hg}$ group averaged about half the $\mathrm{MeHg}$ exposure of the high-mixed group. Exposure levels, especially for MeHg, were much lower at the time of examination and were therefore not considered. Along with PCB, the pesticide metabolite 2,2-bis(4-chlorophenyl)-1,1-dichloroethene ( $p, p^{\prime}$-DDE) biomagnifies in pilot whale blubber, and the two persistent pollutants showed similar concentrations in cord tissue from the 12 subjects (average ratio, 0.97), with a correlation coefficient of 0.94 .

\subsection{Imaging methods}

All participants underwent structural and functional MRI studies at the McLean Brain Imaging Center in Belmont, MA. The examiners were blinded to the exposure status of the subjects.

Conventional MRIs were acquired on all participants to ensure there were no structural brain abnormalities. Scans were acquired using a 1.5 Tesla General Electric Signa (modified by Advanced NMR, Milwaukee, WI) whole body imaging device (software level 4.8). A T1weighted mid-sagittal localizer image was followed by double spin-echo (DSE) $3 \mathrm{~mm}$ axial slices of whole brain $(256 \times 256$ matrix, TR $=3000 \mathrm{~ms}, \mathrm{TE}=30$ and $8 \mathrm{~ms}, 24-\mathrm{cm}$ FOV with two interleaved acquisitions resulting in 108 contiguous DSE slices; voxel dimensions = $0.975 \mathrm{~mm} \times 0.97 \mathrm{~mm} \times 3 \mathrm{~mm}$ ). A 3D Fourier transform spoiled gradient-recalled acquisition (3 DFT SPGR) was also used to generate images with good contrast between gray matter and white matter (Shenton et al., 1992) $(1241.5 \mathrm{~mm}$ thick coronal slices; TR = $35 \mathrm{~ms}, \mathrm{TE}=5 \mathrm{~ms}$ with one repetition; flip angle $=45^{\circ} ; 256 \times 256$ matrix; voxel dimensions $=0.975 \mathrm{~mm} \times 0.975 \mathrm{~mm} \times 1.5 \mathrm{~mm}$ ).

The fMRI study protocol consisted of a series of four behavioral tasks using the same imaging device as above and a quadrature head coil receiver system using a modified echoplanar imaging technique (approximately 15 continuous slices; thickness $=6 \mathrm{~mm}$ ). A series of 50 sequential images were obtained during the tasks. Images were collected every $3 \mathrm{~s}$ using a gradient echo pulse sequence $\left(\mathrm{TE}=40 \mathrm{~ms}\right.$, flip angle $=75^{\circ}$; image matrix $=64 \times$ 128 with a $3 \mathrm{~mm} \times 3 \mathrm{~mm}$ in plane resolution). The fMRI protocols were sequential task activation paradigms of $30 \mathrm{~s}$ resting baseline followed by alternating active and resting states in 30-s intervals, resulting in total paradigm lengths of $150 \mathrm{~s}$.

The tasks included motor and visual organization tasks, naming, and a passive visual stimulation paradigm. These tasks were selected because extensive prior research has shown a significant relationship between higher exposure to MeHg and/or PCBs and lower performance on these tasks or on similar tests that assess the same neuropsychological domains (Grandjean et al., 2006; Rice, 2006) Although the tasks were adapted for use in the scanning environment, where movement is constricted, the naming and visual organization tasks produced highly complex activation patterns that proved difficult to analyze in the small group of subjects. A major limitation of fMRI is that observed activation may be a result of activation in multiple neural circuits though often interpreted as activation of a single cognitive task. Both naming and visual organization are complex cognitive tasks which likely recruit multiple neural circuits resulting in fMRI activation patterns that require 
a larger sample size in order to determine more definitive activation patterns. In this paper, we therefore report the results for two tasks which are less complex, photic stimulation and finger tapping, as processing of each of these tasks is known to be mediated by brain structures that show pathological changes at autopsy in cases of clinical MeHg poisoning (Choi, 1989; Davis et al., 1994; Takeuchi et al., 1962). These two tasks, which are highly robust for use in fMRI (Witt et al., 2008; Gratton et al., 1997), are described below.

Photic stimulation-The participant was asked to open his eyes and lie quietly while data were obtained over a two and a half minute period consisting of two 30-s cycles of darkness alternating with two $30-\mathrm{s}$ cycles of binocular, $8 \mathrm{~Hz}$ patterned flash photic stimulation produced by goggles with light emitting diodes. This sequence was included because it requires only passive viewing and does not require movement, motivation or attention.

Motor task - left and right finger tapping-The participant was asked to touch each finger to his thumb in a sequential, repetitive procedure during the activation periods. During the relaxation phase, the participant was asked to relax and not move his fingers. The task was performed with the right hand (right finger tapping, RFT) then repeated as a separate task with the left hand (left finger tapping, LFT). This task is robust, has demonstrated clear activation sites, and produces easily detectable signal changes for all participants.

\subsection{Data analysis}

Statistical parametric maps (SPMs) were generated for each participant using SPM99 (Friston et al., 1995a, b) (from the Wellcome Department of Cognitive Neurology, London, UK) implemented in Matlab (The Mathworks Inc., Sherborn, MA, USA). The functional data sets were motion corrected within SPM99 using the first image as the reference then normalized to a standard template from Montreal Neurological Institute (MNI). The normalized data sets were first resampled to $2 \mathrm{~mm} \times 2 \mathrm{~mm} \times 2 \mathrm{~mm}$ within MNI space using sinc interpolation and then smoothed using a $4 \mathrm{~mm} \times 4 \mathrm{~mm} \times 4 \mathrm{~mm}$ Full Width at Half Maximum Gaussian smoothing kernel (Smith, 2002). A 150-s box-car waveform, convolved with hemodynamic response function, was used as the reference paradigm. Using general linear model and the hemodynamically corrected reference paradigm, the $T$-score values were calculated for each voxel and the SPMs were generated.

In order to determine the differences in activation between the groups (each compared to the low, mixed group), a second-level paired $t$-test was performed. Since we had only three subjects per group, the SPM group maps were generated using a fixed-effects model with the individual contrast maps (Holmes and Friston, 1998). The resulting maps were thresholded at $T=3.5(p<0.0003)$ for left and right finger tapping paradigms and at $T=5.0$ $(p<0.0001)$ for photic stimulation. The cluster-size threshold was set at 20 voxels. The location, size, and the strength of activation ( $T$-score) were calculated for each activation cluster in SPM99. Anatomical regions were determined for activation maxima using the Talairach Daemon (Lancaster et al., 1997, 2000). The analysis was repeated for each task paradigm. 


\section{Results}

All MRI scans were visually assessed for clinical and structural abnormalities by a neuroradiologist and all were read as structurally normal. Due to the complexity of analyzing and describing all four exposure groups on the behavioral tasks, this presentation focuses on the comparison of the three boys with high exposure to both MeHg and PCB with the three with low, mixed exposure.

Photic stimulation yielded significant activation bilaterally in the occipital lobes for both groups of participants. The group with low exposure showed the normal pattern of greatest activation in the visual association cortex (Brodmann's areas (BAs) 18 and 19) (Fig. 1). In contrast, the group with high, mixed $\mathrm{MeHg} / \mathrm{PCB}$ exposure showed greatest activation in BA 17 , primary visual cortex, and a portion of the mesial aspects of area 18. A paired $t$-test revealed significant bilateral activation within the visual association cortex (BA 19), and to a lesser extent, the right temporal and frontal lobes, for the high exposure group compared to the low exposure group (Table 2). Examination of the fMRI activation for those with only high $\mathrm{MeHg}$ (low PCB exposure) versus those with only high PCB exposure (low MeHg exposure) yielded little difference between the two groups though the high PCB group showed greater activation in the right posterior cingulate gyrus while the high $\mathrm{MeHg}$ group showed greater activation in the right occipital lobe.

Visual inspection of the activation patterns during the finger tapping task performed with the left hand (Fig. 1) in the group with low exposure revealed the typical pattern of activation observed in a simple motor task. There was significant activation in the premotor and motor cortex of the right hemisphere, contralateral to the finger movement. In contrast, the activation pattern visualized for the high, mixed exposure group revealed activation in the same regions, but the activation was bilateral rather than unilateral. The largest differences in activation between the two groups were seen ipsilateral to the side of the finger tapping in the frontal regions, including the motor cortex and the periventricular white matter adjacent to the lateral ventricle that contains fibers of the pyramidal tract. This finding was more dramatic for the left hand than finger tapping with the right hand (Tables 3 and 4). Examination of the fMRI activation for those with only high MeHg versus those with only high PCB exposure yielded little difference between the two groups with the exception that the high PCB group showed comparatively greater activation in the ipsilateral premotor and sensory cortex areas during the RFT task.

\section{Discussion}

To our knowledge, this is the first attempt to use functional imaging in children with prenatal exposure to $\mathrm{MeHg}$ and $\mathrm{PCBs}$. Adolescents with the highest prenatal exposures to $\mathrm{MeHg}$ and PCB show significant differences in brain activation patterns compared to those with the lowest exposure. These findings demonstrate the utility of this non-invasive technique and provide confirmatory evidence of the exposure-associated CNS dysfunction that has been documented in the Faroese cohort and other groups of children with exposures to these contaminants (Cordier et al., 2002; Dahl et al., 1996; Grandjean et al., 1997). 
In children with no history of toxicant or other brain insults, photic stimulation produces focal activation in the visual association areas (BA 18 and 19) (Kang et al., 2003). As shown in Fig. 1, the pattern of activation demonstrated by the low exposure group for the photic stimulation paradigm was consistent with this expectation. In contrast, the high exposure group showed generally more activation in the occipital lobe and right temporal lobe than the low exposure group, with comparatively less activation in BA 18 and 19 and significantly more activation in the primary visual cortex (BA 17). This represented an atypical pattern of neural activation for passive viewing of photic stimuli, and suggests that there may be toxicant-related damage to visual association areas among children with high exposures, possibly representing brain plasticity. In cases of clinical $\mathrm{MeHg}$ poisoning, pathological changes in the brain are especially prominent in the occipital lobes (Choi, 1989; Davis et al., 1994; Takeuchi et al., 1962).

Brain activation during the finger tapping task also showed significant differences between the groups. The children with low mixed exposure showed the normal pattern of brain activation, i.e., focal activation in premotor and motor areas of the brain contralateral to the active finger. In contrast, the highly exposed boys showed activation of bilateral motor areas when carrying out finger tapping with one hand. This finding may reflect disordered brain specialization; a finding which has also been seen in children with childhood lead exposure during a test involving language (Yuan et al., 2006). In fatal cases of MeHg poisoning, neuropathological changes include the motor cortex (Takeuchi et al., 1962). Incomplete lateralization has been documented in subjects with prenatal exposure to an endocrine disrupting agent (Smith and Hines, 2000). Both MeHg (Tan et al., 2009) and PCBs (Rasmussen et al., 2003) have been reported to exert endocrine disrupting effects.

Overall, this study showed normal brain activation patterns in the low exposure group, while the highly exposed group revealed different patterns of brain activation and activation of more parts of the brain in response to the tasks. The group with high PCB exposure only tended to show slightly greater activation on tasks of photic stimulation and right finger tapping than did the boys who had high MeHg exposure only. However, any attribution of the effects to $\mathrm{MeHg}$ and/or PCBs is not possible due to the small size of the study group and differences in exposure levels. Because $p, p^{\prime}$-DDE correlated very closely with PCB and is less clearly documented as a developmental neurotoxicant (Grandjean and Landrigan, 2006), this pollutant was not further considered. Likewise, no attempt was made to link the imaging findings to specific neuropsychological test results of the subjects examined.

Although exposure-related deficits in motor speed and visually mediated tasks have been documented for the full cohort (Debes et al., 2006; Grandjean et al., 1997), which are in accordance with the rather dramatic imaging findings, the boys did not appear to have abnormalities serious enough to affect their visual and motor function in daily living. This suggests that the activation patterns revealed by fMRI may, in part, reflect adaptive brain responses to developmental toxicity on brain structures.

Results must be interpreted with caution due to the small number of participants and a fixedeffects analysis. However, the results are intriguing and statistically significant despite the small group size. They suggest that further fMRI investigations of children exposed to 
$\mathrm{MeHg}$ and PCBs are warranted and that this technique deserves to be used in neurotoxicity studies in general.

\section{Conclusions}

This pilot study utilized functional MRI techniques to observe activation of specific brain areas during behavioral tasks in boys with well-characterized prenatal exposure to $\mathrm{MeHg}$ and PCB. The method revealed clear differences in brain activation between the boys with high exposure and those with low exposure on tasks requiring visual processing (photic stimulation) and manual motor movement (finger-tapping). The greater and more widespread brain activation in the high exposure group suggests that adolescents with high prenatal exposure required more brain resources to complete these two simple tasks and that differential specialization of brain areas may have occurred following prenatal neurotoxicant exposure. These findings support the utility of fMRI as a probe for CNS injury associated with developmental exposure to neurotoxicants.

\section{Acknowledgements}

This work was funded by a grant from the Danish Medical Research Council and by the National Institute of Environmental Health Sciences (ES09797). The contents of this paper are solely the responsibility of the authors and do not necessarily represent the official views of the NIEHS, NIH or any other funding agency. The authors wish to thank the 12 Faroese adolescents who participated in this project, their parents, and the Faroese chaperones (Sara Weihe and Johan Peter Weihe).

\section{Abbreviations}

$\begin{array}{ll}\text { fMRI } & \text { functional magnetic resonance imaging } \\ \text { SPMs } & \text { statistical parametric maps } \\ \text { MNI } & \text { Montreal Neurological Institute }\end{array}$

\section{References}

Bellinger DC, Trachtenberg F, Barregard L, Tavares M, Cernichiari E, Daniel D, et al. Neuropsychological and renal effects of dental amalgam in children: a randomized clinical trial. JAMA. 2006; 295(15):1775-1783. [PubMed: 16622139]

Canfield RL, Henderson CR Jr, Cory-Slechta DA, Cox C, Jusko TA, Lanphear BP. Intellectual impairment in children with blood lead concentrations below 10 microg per deciliter. N Engl J Med. 2003; 348(16):1517-1526. [PubMed: 12700371]

Choi BH. The effects of methylmercury on the developing brain. Prog Neurobiol. 1989; 32(6):447470. [PubMed: 2664880]

Cordier S, Garel M, Mandereau L, Morcel H, Doineau P, Gosme-Seguret S, et al. Neurodevelopmental investigations among methylmercury-exposed children in French Guiana. Environ Res. 2002; 89(1): 1-11. [PubMed: 12051779]

Dahl R, White RF, Weihe P, Sorensen N, Letz R, Hudnell HK, et al. Feasibility and validity of three computer-assisted neurobehavioral tests in 7-year-old children. Neurotoxicol Teratol. 1996; 18(4): 413-419. [PubMed: 8866532]

Davis LE, Kornfeld M, Mooney HS, Fiedler KJ, Haaland KY, Orrison WW, et al. Methylmercury poisoning: long-term clinical, radiological, toxicological, and pathological studies of an affected family. Ann Neurol. 1994; 35(6):680-688. [PubMed: 8210224] 
Debes F, Budtz-Jorgensen E, Weihe P, White RF, Grandjean P. Impact of prenatal methylmercury exposure on neurobehavioral function at age 14 years. Neurotoxicol Teratol. 2006; 28(5):536-547. [PubMed: 17067778]

Friston KJ, Ashburner J, Frith CD, Poline JB, Heather JD, Frackowiak RSJ. Spatial registration and normalization of images. Hum Brain Mapp. 1995a; 2:165-189.

Friston KJ, Holmes AP, Worsley KJ, Poline JB, Frith C, Frackowiak RSJ. Statistical parametric maps in functional imaging: a general linear approach. Hum Brain Mapp. 1995b; 2:189-210.

Grandjean, P.; Cordier, S.; Kjellström, T. Developmental neurotoxicity associated with dietary exposure to methylmercury from seafood and freshwater fish. In: Bellinger, DC., editor. Human developmental neurotoxicology. New York: Taylor and Francis; 2006. p. 25-42.

Grandjean P, Landrigan PJ. Developmental neurotoxicity of industrial chemicals. Lancet. 2006; 368(9553):2167-2178. [PubMed: 17174709]

Grandjean P, Weihe P, Burse VW, Needham LL, Storr-Hansen E, Heinzow B, et al. Neurobehavioral deficits associated with PCB in 7-year-old children prenatally exposed to seafood neurotoxicants. Neurotoxicol Teratol. 2001; 23(4):305-317. [PubMed: 11485834]

Grandjean P, Weihe P, White RF, Debes F, Araki S, Yokoyama K, et al. Cognitive deficit in 7-yearold children with prenatal exposure to methylmercury. Neurotoxicol Teratol. 1997; 19(6):417428. [PubMed: 9392777]

Gratton G, Fabiani M, Corballis PM, Hood DC, Goodman-Wood MR, Hirsch J, et al. Fast and localized event-related optical signals (EROS) in the human occipital cortex: comparisons with the visual evoked potential and fMRI. NeuroImage. 1997; 6:168-180. [PubMed: 9344821]

Holmes AP, Friston KJ. Generalizability, random effects, and population inference. NeuroImage. 1998; 7:S754.

Jacobson JL, Jacobson SW, Humphrey HE. Effects of in utero exposure to polychlorinated biphenyls and related contaminants on cognitive functioning in young children. J Pediatr. 1990; 116(1):3845. [PubMed: 2104928]

Kang HC, Burgund ED, Lugar HM, Petersen SE, Schlaggar BL. Comparison of functional activation foci in children and adults using a common stereotactic space. Neuroimage. 2003; 19(1):16-28. [PubMed: 12781724]

Lancaster JL, Summerlin JL, Rainey L, Freitas CS, Fox PT. The Talairach Daemon: a database server for Talairach Atlas Labels. NeuroImage. 1997; 5:S633.

Lancaster JL, Woldorff MG, Parsons LM, Liotti M, Freitas ES, Rainey L, et al. Automated Talairach Atlas labels for functional brain mapping. Hum Brain Mapp. 2000; 10(3):120-131. [PubMed: 10912591]

Papanicolaou, AC. Fundamentals of functional brain imaging: a guide to the methods and their applications to psychology and behavioral neurosciences. Netherlands: Swets and Zeitlinger; 1998.

Rasmussen TH, Nielsen F, Andersen HR, Nielsen JB, Weihe P, Grandjean P. Assessment of xenoestrogenic exposure by a biomarker approach: application of the E-Screen bioassay to determine estrogenic response of serum extracts. Environ Health. 2003; 2(1):12. [PubMed: 14613489]

Rice, DC. Effects of PCB exposure on neuropsychological function in epidemiological studies: issues and research. In: Bellinger, DC., editor. Human developmental neurotoxicology. New York: Taylor and Francis; 2006. p. 43-66.

Shenton M, Kikinia R, Jolesz F, Pollak S, LeMay M, Wible C, et al. Abnormalities of the left temporal lobe and thought disorder in schizophrenia. New Engl J Med. 1992; 327:604-612. [PubMed: 1640954]

Smith LL, Hines M. Language lateralization and handedness in women prenatally exposed to diethylstilbestrol (DES). Psychoneuroendocrinology. 2000; 25(5):497-512. [PubMed: 10818283]

Smith, SM. Preparing fMRI data for statistical analysis. In: Jezzard, P.; Matthews, PM.; Smith, SM., editors. Functional MRI: an introdution to methods. New York: Oxford University Press; 2002.

Takeuchi T, Moriwaka N, Matsumoto H, Shiraishi Y. A pathological study of Minamata disease in Japan. Acta Neuropathol. 1962; 2:40-57.

Tan SW, Meiller JC, Mahaffey KR. The endocrine effects of mercury in humans and wildlife. Crit Rev Toxicol. 2009; 39(3):228-269. [PubMed: 19280433] 
White R. Neuropsychological assessments in children from a longitudinal perspective for the National Children's Study. 2004

Witt ST, Laird AR, Meyerand ME. Functional neuroimaging correlates of finger-tapping task variations: an ALE meta-analysis. NeuroImage. 2008; 42:343-356. [PubMed: 18511305]

Yuan W, Holland SK, Cecil KM, Dietrich KN, Wessel SD, Altaye M, et al. The impact of early childhood lead exposure on brain organization: a functional magnetic resonance imaging study of language function. Pediatrics. 2006; 118(3):971-977. [PubMed: 16950987] 


\section{Photic Stimulation}

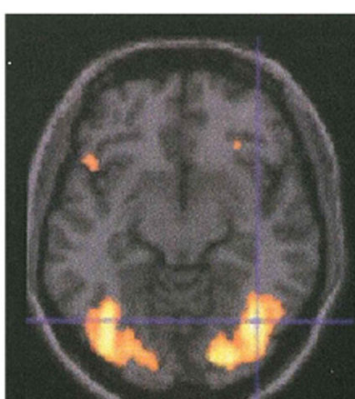

High MeHg

and

High PCB

Group

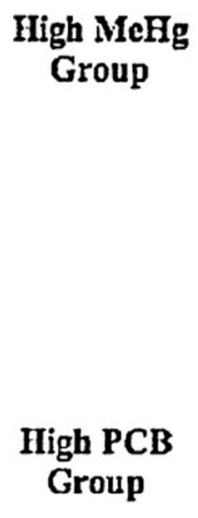

\section{Left Finger Tapping}

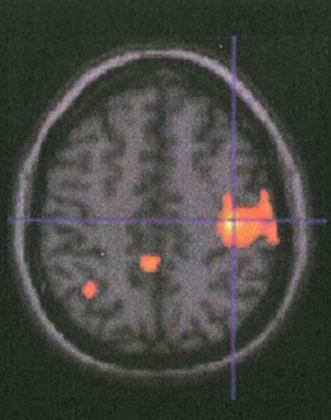

Right Finger Tapping

Right Finger Tapping

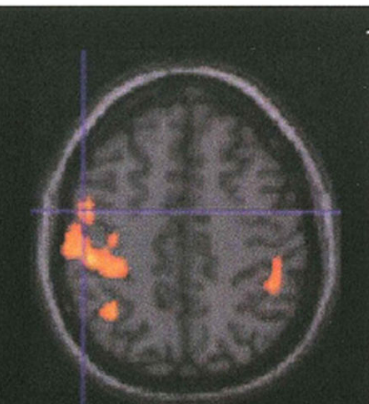

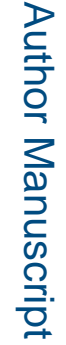

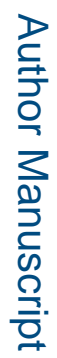

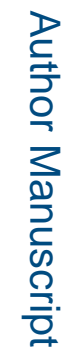

Fig. 1.

Average activation by exposure group during tasks of photic stimulation and finger tapping. The control group refers to the 3 subjects with low MeHg and low PCB exposure (left hemisphere is on left side of brain slices). 


\section{Table 1}

Mercury ( $\mu \mathrm{g} / \mathrm{L}$ cord blood) and PCB (ng/g wet weight of cord tissue) concentrations reflecting prenatal exposure levels in four groups of Faroese adolescents examined (three boys in each group).

\begin{tabular}{lll}
\hline & Mercury & PCB \\
\hline High mercury group & $30.70-67.70$ & $0.22-0.36$ \\
High PCB group & $10.10-13.30$ & $3.93-6.08$ \\
High mixed group & $81.30-114.00$ & $4.60-6.91$ \\
Low mixed group & $4.30-13.80$ & $0.40-0.53$ \\
\hline
\end{tabular}




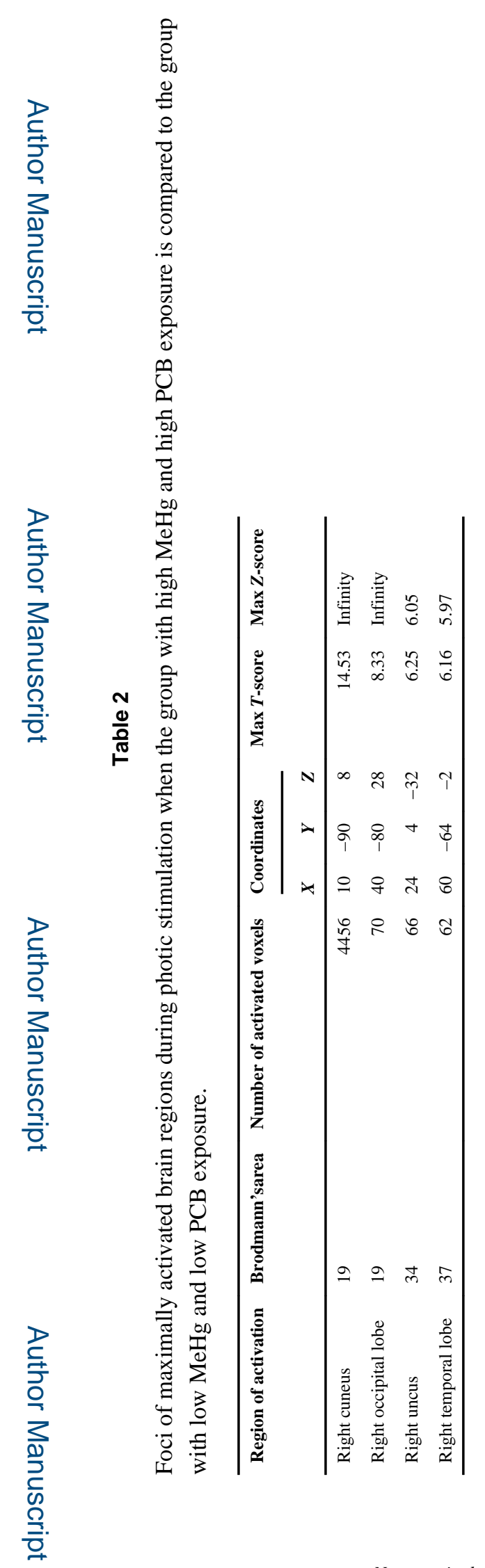

Neurotoxicology. Author manuscript; available in PMC 2015 April 27. 


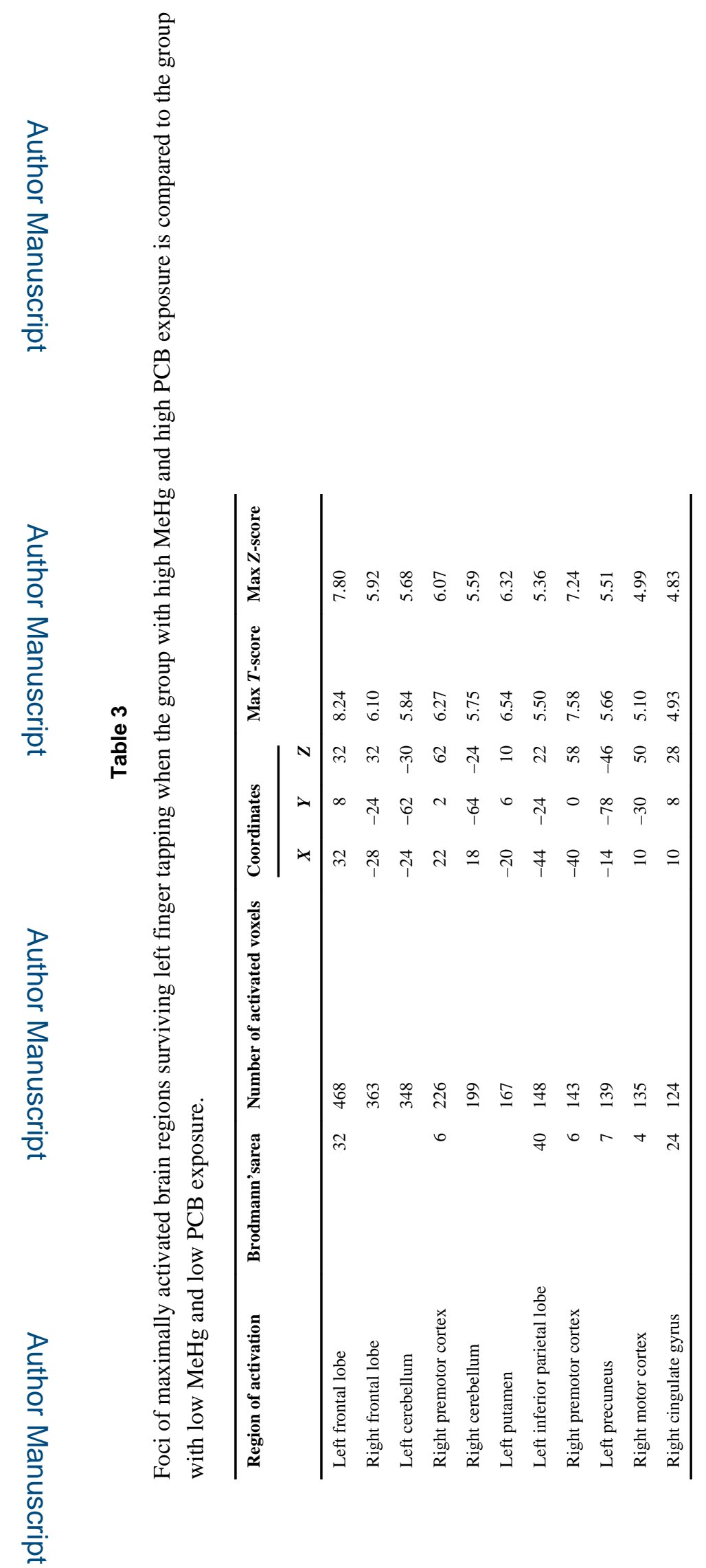

Neurotoxicology. Author manuscript; available in PMC 2015 April 27. 


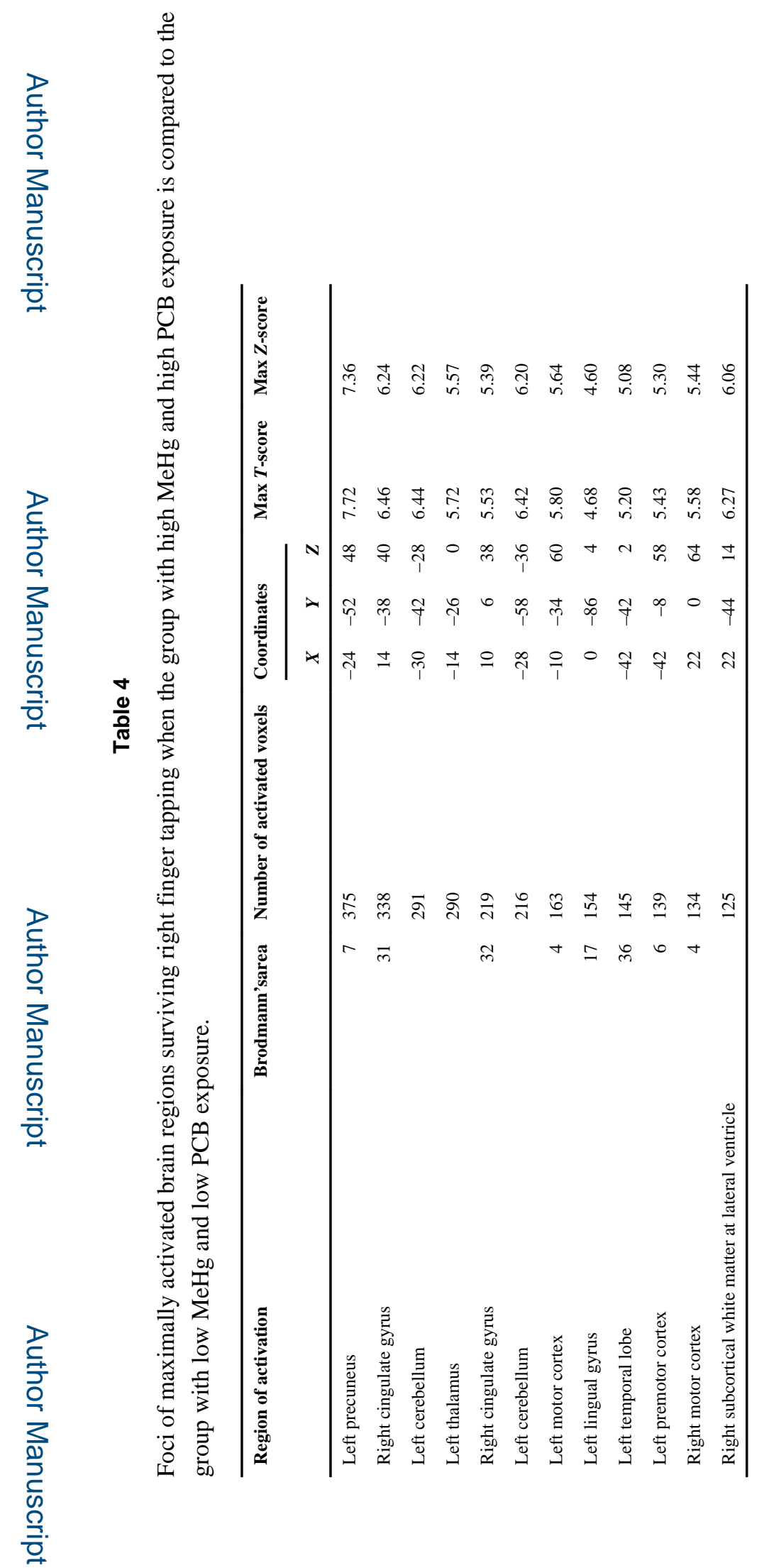

Neurotoxicology. Author manuscript; available in PMC 2015 April 27. 